\title{
Patent-Investment Games under Asymmetric Information
}

\author{
Chi Man Leung and Yue Kuen Kwok ${ }^{1}$ \\ Department of Mathematics, Hong Kong University of Science and \\ Technology, Hong Kong
}

\begin{abstract}
This paper analyzes preemptive patenting in a two-stage real options game where an incumbent firm competes with a potential entrant firm for the patent of a substitute product in a product market with profit flow uncertainty. The incumbent suffers loss of monopoly in the product market if the entrant acquires the patent of a substitute product and later commercializes the product. Our patent-investment game model assumes that the entrant has complete information on the incumbent's commercialization cost while the incumbent only knows the distribution of the entrant's cost. We investigate the impact of information asymmetry on the preemption strategies adopted by the two competing firms on patenting the substitute product by comparing the optimal preemption strategies and the real option value functions of the two competing firms under complete information and information asymmetry. Our analysis reveals that the informationally disadvantaged incumbent always suffers from loss in its real option value of investment since it tends to act more aggressively in competing for the patent. On the other hand, the real option value of investment of the informationally advantaged entrant may be undermined or enhanced. The incumbent's aggressive response under information asymmetry may lead to reversal of winner in the patent race. We also examine how information asymmetry may affect the occurrence of sleeping patent and the corresponding expected duration between the two stages of patenting and product commercialization.
\end{abstract}

Keywords: patent-investment model, asymmetric information, real options game, sleeping patents

\footnotetext{
${ }^{1}$ Correspondence author; email: maykwok@ust.hk
} 


\section{Introduction}

We consider a patent-investment game model that analyzes the preemption strategies of two competing firms (incumbent and entrant) on patenting a product under information asymmetry. The incumbent firm is now operating a monopolized product with profit flow uncertainty. The monopoly can be undermined by the entry of a new entrant firm in the product market through patenting and commercialization of a substitute product. On the other hand, the incumbent can maintain its monopoly status by blocking the entrant's entry through acquisition of the patent of the substitute product. There is a fixed common patent fee for acquisition of the patent for either firm. However, the commercialization cost of the substitute product differs between the two firms. Furthermore, we assume that the entrant has complete information on the incumbent's commercialization cost while the incumbent has only the knowledge of the distribution of the entrant's commercialization cost. Upon launching of the substitute product by the entrant, the profit flow rate of the incumbent is reduced due to loss of monopoly in the product market. However, if the substitute product is launched by the incumbent, the incumbent's profit flow rate is enhanced since it operates on two products. It is possible that the patent is acquired in the first stage and the subsequent commercialization of the product in the second stage is delayed, a phenomenon that is commonly called "sleeping patent".

Patent races, sleeping patents, and economic valuation of patents have been explored in various works in recent decades (Gilbert and Newbery, 1982; Harris and Vickers, 1985; Lambrecht, 2000; Sereno, 2008). Lambrecht and Perraudin (2003) study real investment options and preemption under twosided incomplete information when both competing firms only have knowledge of the distribution of the investment cost of their respective competitor. The two-stage patent-investment game model in this paper is an extension of Hsu-Lambrecht's one-stage patent race model under asymmetric cost information (2007) and Leung-Kwok's two-stage patent-investment race model under complete cost information (2010). Discussions on the significance of these models for analyzing patent races with reference to preemptive patenting and revenue flow uncertainty can be found in the two papers (Hsu and Lambrecht, 2007; Leung and Kwok, 2010). As pointed by various works on real options game theoretic models under asymmetric information (Zhu and Weyant, 2003; Thijssen et al., 2006), the equilibrium strategies under asymmetric information can be quite different from those under complete 
information. Information asymmetry may lead to different incentives and preemption behaviors of the competing firms since the informationally disadvantaged firm may be induced to respond more aggressively under certain economic scenarios. In this paper, we manage to obtain numerous interesting results beyond the earlier Leung-Kwok's two-stage patent-investment model under complete information. It is possible that the outcome of the eventual winner in the patent race may change when the incumbent does not have exact information on the entrant's cost. In general, the incumbent's aggressive response to its informationally disadvantaged status would undermine the real option value of investment of both competing firms. However, we are able to find exceptions that the entrant's real option value may be enhanced when the incumbent's belief of the entrant's commercialization cost is biased high. While both Hsu-Lambrecht's one-stage model and our two-stage model are under information asymmetry, our model provides a wider set of optimal preemption strategies and exhibits various forms of impact on the real investment option values. When only one-stage patenting is assumed, the informationally advantaged entrant never suffers loss in its real option value. Also, the one-stage model reveals that if the entrant wins, its winner status would not be affected by the aggressive action of the incumbent. However, these results are not always true in our two-stage model. Other real options game theoretical models under information asymmetry (Zhu and Weyant, 2003) also exhibit potential swapping of the winner in the game. In addition, our two-stage model encompasses more detailed analysis of various sleeping patent phenomenon under information asymmetry, preemptive patenting, and revenue flow uncertainty.

The paper is organized as follows. In the next section, we formulate the two-stage patent-investment real options game model with asymmetric information in the commercialization costs of the incumbent firm and entrant firm (challenger). In Section 3, we examine the range of trigger thresholds within which the strategic patent trigger of each firm lies. The upper bound of the strategic patent trigger is shown to be simply the corresponding nonstrategic trigger threshold. The lower bound of the strategic patent trigger is the threshold at which the firm breaks even. That is, at the lower bound of the patent trigger, the sum of real option value of acquisition of the patent and the benefit of avoiding loss when preempted equals the patent cost. In Section 4, we examine the optimal preemption strategies of both firms and consider how information asymmetry affects these preemption strategies. In particular, we analyze how the aggressive response of the informationally 
disadvantaged incumbent may affect the real option values of investment and the preemption triggers of both firms. We also analyze the impact of information asymmetry on the sleeping patent phenomenon, whether the winner firm chooses strategically to shorten or lengthen the expected duration between the two stages of patent and product commercialization. In the last section, various conclusive remarks of the paper are presented.

\section{Formulation of the two-stage patent-investment model}

We adopt a similar two-stage patent-investment real game model as proposed in Leung and Kwok (2010) except that cost information asymmetry is added in the present new model. The incumbent (Firm $i$ ) is now operating a monopolized product in the market with stochastic profit flow rate $x_{t}$ that is modeled by the following Geometric Brownian process:

$$
d x_{t}=\mu x_{t} d t+\sigma x_{t} d Z_{t} .
$$

Here $\mu$ is the constant drift rate, $\sigma$ is the constant volatility, and $Z_{t}$ is the standard Brownian process. The constant discount rate adopted in the market is $r$. With reference to the usual no-bubble condition, $r$ is taken to be greater than $\mu$.

In our two-stage patent-investment game model, the incumbent is faced with potential entry of the entrant firm (Firm e) into the product market through the operation of a substitute product. The two firms both compete for the patent of the substitute product by paying a common fixed cost $C$ of the patent. The patent serves to block the entry of the competitor. As a consequence, the patent holder then possesses the real option to commercialize the substitute product at a later stage. Let $K_{i}$ and $K_{e}$ denote the additional sunk cost of commercialization of the substitute product required for the incumbent and entrant, respectively. Here, we introduce cost information asymmetry into the model that is similar to Hsu-Lambrecht's one-stage model (2007). We assume that the entrant has full information of the incumbent's commercialization cost $K_{i}$. However, the incumbent only knows that the entrant's commercialization cost $K_{e}$ is drawn from a probability distribution $G\left(K_{e}\right)$ with compact support on $\left[K_{L}, K_{U}\right]$, where $G\left(K_{e}\right)$ is assumed to be continuously differentiable. 
Suppose the entrant purchases the patent and later commercializes the substitute product, the stochastic profit rate received by the entrant is $\pi_{e} x_{t}$, $\pi_{e}>0$. Under such scenario, the product market becomes duopoly with two products offered by the two firms. Subsequently, the incumbent's profit flow rate is then reduced to $\left(1-\pi_{i}^{-}\right) x_{t}$, where $0<\pi_{i}^{-}<1$. If otherwise, when both products are operated by the incumbent, its stochastic profit flow rate is increased to $\left(1+\pi_{i}^{+}\right) x_{t}$, where $\pi_{i}^{+}>0$.

\section{Trigger strategies adopted by the two firms}

Since $x_{t}$ is a Markov process, each firm would adopt a single trigger strategy where the firm chooses optimally to patent and commercialize the substitute product when $x_{t}$ reaches the corresponding equilibrium trigger from below. First, we quote the results on the non-strategic patent and commercialization triggers of the two firms when there is no preemptive threat from its competitor (Leung and Kwok, 2010). Let $x_{j p}^{*}$ and $x_{j c}^{*}$ denote the non-strategic patent trigger and commercialization trigger of Firm $j, j=i, e$, respectively. We have

$$
\begin{gathered}
x_{i p}^{*}=\frac{\beta}{\beta-1} \frac{(r-\mu)\left(C+K_{i}\right)}{\pi_{i}^{+}}, x_{e p}^{*}=\frac{\beta}{\beta-1} \frac{(r-\mu)\left(C+K_{e}\right)}{\pi_{e}}, \\
x_{i c}^{*}=\frac{\beta}{\beta-1} \frac{(r-\mu) K_{i}}{\pi_{i}^{+}}, x_{e c}^{*}=\frac{\beta}{\beta-1} \frac{(r-\mu) K_{e}}{\pi_{e}}
\end{gathered}
$$

where

$$
\beta=\frac{-\left(\mu-\frac{\sigma^{2}}{2}\right)+\sqrt{\left(\mu-\frac{\sigma^{2}}{2}\right)^{2}+2 r \sigma^{2}}}{\sigma^{2}} .
$$

Note that $x_{j p}^{*}>x_{j c}^{*}$ under positive patent cost $C, j=i, e$. For either firm, it chooses to commercialize the product immediately after acquiring the patent when there is no preemptive threat from the competing firm.

Due to preemptive competition, the competing firms may choose strategically to acquire the patent at a lower trigger threshold. Let $x_{j s}^{*}$ denote the strategic patent trigger of Firm $j, j=i, e$. The non-strategic patent trigger $x_{j p}^{*}$ clearly represents the upper bound of $x_{j s}^{*}$, that is, $x_{j s}^{*} \leq x_{j p}^{*}$. On the other hand, the firm never chooses to acquire the patent when the patent cost is higher than the benefits received by the firm upon acquisition of the patent. We determine the corresponding breakeven threshold, commonly called the 
Marshallian trigger, at which the firm is indifferent between acquiring the patent and being preempted. Next, we would like to determine the lower bound on the strategic patent trigger $x_{j s}^{*}$ based on breakeven consideration.

\section{Entrant's Marshallian trigger}

Since the entrant has full information on its own commercialization cost $K_{e}$, the Marshallian trigger $x_{e m}^{*}$ is known to itself. The breakeven trigger threshold is determined by equalizing the real option value of commercialization of the substitute product with the patent cost. When $x_{t}$ assumes the value $x$, the entrant's real option value function $V_{e}(x)$ of holding the patent is known to be (Leung and Kwok, 2010)

$$
V_{e}(x)=\left\{\begin{array}{ll}
\frac{K_{e}}{\beta-1}\left(\frac{x}{x_{e c}^{*}}\right)^{\beta} & \text { for } x<x_{e c}^{*} \\
\frac{\pi_{e} x}{r-\mu}-K_{e} & \text { for } x \geq x_{e c}^{*}
\end{array} .\right.
$$

The entrant's Marshallian trigger $x_{e m}^{*}$ is the unique solution to

$$
V_{e}(x)-C=0 .
$$

Here, $x_{e m}^{*}$ represents the lower bound on the strategic patent trigger $x_{e s}^{*}$ of the entrant firm.

\section{Lower bound on the incumbent's strategic patent trigger}

Based on breakeven consideration, the incumbent strikes the balance between the patent cost and the sum of the real option value of commercialization and the benefit of avoiding the loss in revenue flow upon being preempted. Similar to $V_{e}(x)$, the real option value function of the incumbent holding the patent is given by

$$
V_{i}(x)=\left\{\begin{array}{ll}
\frac{K_{i}}{\beta-1}\left(\frac{x}{x_{i c}^{*}}\right)^{\beta} & \text { for } x<x_{i c}^{*} \\
\frac{\pi_{i}^{+} x}{r-\mu}-K_{i} & \text { for } x \geq x_{i c}^{*}
\end{array} .\right.
$$

Suppose the incumbent is preempted by the entrant, the expected value of loss in revenue flow to the incumbent is $-\frac{\pi_{i}^{-} x}{r-\mu}$ when the entrant has commercialized the substitute product. When the entrant has acquired the patent but not yet commercialized the product (patent remains sleeping), the expected loss is $-\frac{\pi_{i}^{-} x_{e c}^{*}}{r-\mu}\left(\frac{x}{x_{e c}^{*}}\right)^{\beta}$ [see Leung and Kwok (2010)]. Unfortunately, 
the determination of the precise commercialization trigger $x_{e c}^{*}$ depends on the exact information on $K_{e}$. In the present model, the incumbent only knows the distribution of $K_{e}$. Based on the belief that $K_{e}$ assumes some value $K$, where $K_{L} \leq K \leq K_{U}$, the corresponding (negative-valued) expected loss value function $L_{i}(x ; K)$ is given by

$$
L_{i}(x ; K)=\left\{\begin{array}{lc}
-\frac{\pi_{i}^{-} x_{e c}^{*}(K)}{r-\mu}\left[\frac{x}{x_{e c}^{*}(K)}\right]^{\beta} & \text { for } x<x_{e c}^{*}(K) \\
-\frac{\pi_{i}^{-} x}{r-\mu} & \text { for } x \geq x_{e c}^{*}(K)
\end{array},\right.
$$

where $x_{e c}^{*}(K)$ denotes the entrant's commercialization trigger when the entrant's commercialization cost is $K$. The incumbent suffers less loss upon being preempted when $K$ assumes a higher value, so we expect

$$
L_{i}\left(x ; K_{L}\right) \leq L_{i}(x ; K) \leq L_{i}\left(x ; K_{U}\right), K_{L} \leq K \leq K_{U}
$$

The incumbent's real option value $V_{i}(x)$ of holding the patent remains at low value when the profit flow rate is at some sufficiently low level. The incumbent would never choose to acquire the patent at the trigger level $x$ when $V_{i}(x)-C$ is less than the largest expected loss based on the incumbent's belief on $K_{e}$. Since $L_{i}(x ; K)$ is increasing with respect to $K$, so the largest expected loss is given by $L_{i}\left(x ; K_{L}\right)$. In other words, when $x$ is less than the unique root to the following equation:

$$
V_{i}(x)-C-L_{i}\left(x ; K_{L}\right)=0,
$$

preemptive patenting would never be exercised strategically by the incumbent. The above root is seen to be the incumbent's Marshallian trigger that is based on the most conservative belief that $K_{e}$ assumes the lowest value $K_{L}$. For convenience of notation, we use $x_{i m}^{*}\left(K_{L}\right)$ to denote this lower bound on the incumbent's strategic patent trigger $x_{i s}^{*}$. Since it is very likely that the exact value of $K_{e}$ is above $K_{L}$, the incumbent faces with net negative value when it chooses to preempt the entrant at $x_{i m}^{*}\left(K_{L}\right)$. In our later discussion, we generalize the notion of the incumbent's Marshallian trigger to refer to the breakeven trigger between patenting and being preempted for the incumbent at some assumed value of $K_{e}$.

Updating on the distribution of entrant's commercialization cost Similarly, the non-strategic patent trigger of the entrant $x_{e p}^{*}$ has dependence 
on $K_{e}$. Suppose $x_{t}$ has moved above $x_{e p}^{*}\left(K_{L}\right)$ from below and the entrant has not chosen to preempt, then the incumbent can learn from this information to narrow the range of its estimation of $K_{e}$. We let $x_{t}^{\max }$ denote the realized maximum value of $x_{t}$ from time 0 to the current time $t$, where

$$
x_{t}^{\max }=\max _{0 \leq u \leq t} x_{u} .
$$

Based on the monotonicity of $x_{e p}^{*}\left(K_{e}\right)$ as a function of $K_{e}$, the inverse function of $x_{e p}^{*}$ exists and it is formally represented by $x_{e p}^{-1}$ in later discussion. Suppose $x_{t}^{\max }>x_{e p}^{*}\left(K_{L}\right)$ and the entrant has not chosen to preempt, the incumbent then deduces that $K_{e}$ cannot lie within $\left[K_{L}, x_{e p}^{-1}\left(x_{t}^{\max }\right)\right]$; or otherwise preemptive patenting by the entrant has occurred already. Accordingly, the incumbent can narrow the range of $K_{e}$ from $\left[K_{L}, K_{U}\right]$ to $\left(x_{e p}^{-1}\left(x_{t}^{\max }\right), K_{U}\right]$. Given that $x_{t}^{\max }>x_{e p}^{*}\left(K_{L}\right)$, the probability distribution of $K_{e}$ can be updated using Bayes' rule as follows (Hsu and Lambrecht, 2007):

$$
\hat{G}\left(K \mid x_{t}^{\max }\right)=\frac{G(K)-G\left(x_{e p}^{-1}\left(x_{t}^{\max }\right)\right)}{1-G\left(x_{e p}^{-1}\left(x_{t}^{\max }\right)\right)}, \quad x_{e p}^{-1}\left(x_{t}^{\max }\right) \leq K \leq K_{U} .
$$

The incumbent's lower bound on the patent trigger is then updated from $x_{i m}^{*}\left(K_{L}\right)$ to a higher level $x_{i m}^{*}\left(x_{e p}^{-1}\left(x_{t}^{\max }\right)\right)$.

\section{Strategic interaction of preemption strategies}

The preemption strategy adopted by the informationally disadvantaged incumbent is strongly influenced by the most conservative breakeven triggers of both firms based on the belief that the entrant's commercialization cost $K_{e}$ assumes the lowest value $K_{L}$.

When $x_{i m}^{*}\left(K_{L}\right)<x_{e m}^{*}\left(K_{L}\right)$, the incumbent finds itself never being preempted if it chooses to invest at any trigger between $x_{i m}^{*}\left(K_{L}\right)$ and $x_{e m}^{*}\left(K_{L}\right)$. This is because the entrant never chooses to preempt the incumbent within the range $\left[x_{i m}^{*}\left(K_{L}\right), x_{e m}^{*}\left(K_{L}\right)\right)$ even under the most cost-efficient scenario where $K_{e}$ assumes the lowest value $K_{L}$. How about the incumbent's choice of a higher strategic preemption trigger $x_{i s}^{*}$ that is above $x_{e m}^{*}\left(K_{L}\right)$ ? The adoption of this strategy would lead to a finite probability of being preempted since it may occur that $x_{e m}^{*}\left(K_{e}\right)$ is less than $x_{i s}^{*}$ as chosen by the incumbent. On the other hand, when $x_{i m}^{*}\left(K_{L}\right) \geq x_{e m}^{*}\left(K_{L}\right)$, the same argument shows that there always exists a finite probability of preemption by the entrant since $x_{i s}^{*}$ must be at or above $x_{i m}^{*}\left(K_{L}\right)$ which in turns leads to $x_{i s}^{*} \geq x_{e m}^{*}\left(K_{L}\right)$. 
To each competing firm, the preemption strategy is dictated by striking the balance between the real option value of waiting (prior to patenting) and the real option value upon immediate patenting. We consider the incumbent strategic real option value of waiting $W_{i}\left(x \mid x_{t}^{\max }, x_{i s}^{*}\right)$ conditional on the information on the realized maximum $x_{t}^{\max }$, incumbent's choice of strategic patent trigger $x_{i s}^{*}$ and $x_{t}=x$. Note that $x_{i s}^{*}$ would not be chosen to be above $x_{e p}^{*}\left(K_{U}\right)$, which is the upper bound for the entrant's patent trigger. Also, $x_{i s}^{*}$ must be chosen to be at or above $x_{i m}^{*}\left(K_{L}\right)$. When $x_{i s}^{*}$ is chosen to be below $x_{e m}^{*}\left(K_{L}\right)$, there is no preemptive threat from the entrant, so the incumbent always wins. The more interesting case corresponds to the choice of $x_{i s}^{*}>x_{e m}^{*}\left(K_{L}\right)$, in which case we consider whether the given choice of $x_{i s}^{*}$ is optimal or otherwise.

Incumbent's real option value of waiting

When $K_{e}$ lies between $x_{e m}^{-1}\left(x_{i s}^{*}\right)$ and $K_{U}$, the incumbent wins the game. On the other hand, when $\max \left\{K_{L}, x_{e p}^{-1}\left(x_{t}^{\max }\right)\right\}<K_{e}<x_{e m}^{-1}\left(x_{i s}^{*}\right)$, the entrant wins by adopting epsilon-preemption at $x_{i s}^{*}-\varepsilon$ if $x_{e p}^{*}\left(K_{e}\right) \geq x_{i s}^{*}$ or optimal entry at $x_{e p}^{*}\left(K_{e}\right)$ if $x_{e p}^{*}\left(K_{e}\right)<x_{i s}^{*}$. Summarizing the above observations and taking into consideration of potential updating of the lower bound of $K_{e}$ through the knowledge of $x_{t}^{\max }$, we deduce that the incumbent's real option value of waiting conditional on a given choice of $x_{i s}^{*}$ is given by

$$
\begin{aligned}
W_{i}\left(x \mid x_{t}^{\max }, x_{i s}^{*}\right)= & \int_{\max \left\{K_{L}, x_{e p}^{-1}\left(x_{t}^{\max }\right)\right\}}^{\max \left\{K_{L}, x_{e p}^{-1}\left(x_{i s}^{*}\right)\right\}} L_{i}\left(x_{e p}^{*}(K) ; K\right)\left[\frac{x}{x_{e p}(K)}\right]^{\beta} d \bar{G}(K) \\
& +\int_{\max \left\{K_{L}, x_{e p}^{-1}\left(x_{i s}^{*}\right)\right\}}^{x_{e m}^{-1}\left(x_{i s}^{*}\right)} L_{i}\left(x_{i s}^{*} ; K\right)\left(\frac{x}{x_{i s}^{*}}\right)^{\beta} d \bar{G}(K) \\
& +\int_{x_{e m}^{-1}\left(x_{i s}^{*}\right)}^{K_{U}}\left[V_{i}\left(x_{i s}^{*}\right)-C\right]\left(\frac{x}{x_{i s}^{*}}\right)^{\beta} d \bar{G}(K)
\end{aligned}
$$

where the distribution function of $K_{e}$ with potential updating is given by

$$
\bar{G}(K)=\left\{\begin{array}{ll}
\hat{G}(K) & \text { if } x_{t}^{\max } \geq x_{e p}^{*}\left(K_{L}\right) \\
G(K) & \text { if } x_{t}^{\max }<x_{e p}^{*}\left(K_{L}\right)
\end{array} .\right.
$$

The first two terms represent the contributions (negative-valued) to the waiting value $W_{i}\left(x \mid x_{t}^{\max }, x_{i s}^{*}\right)$ due to expected losses that correspond to entrant's optimal entry at $x_{e p}^{*}(K)$ when $K_{e} \in\left[\max \left\{K_{L}, x_{e p}^{-1}\left(x_{t}^{\max }\right)\right\}, \max \left\{K_{L}, x_{e p}^{-1}\left(x_{i s}^{*}\right)\right\}\right)$ and entrant's strategic entry at $x_{i s}^{*}$ when $K_{e} \in\left[\max \left\{K_{L}, x_{e p}^{-1}\left(x_{i s}^{*}\right)\right\}, x_{e m}^{-1}\left(x_{i s}^{*}\right)\right]$, 
respectively. The last term represents the incumbent's real value of holding the patent when $K_{e} \in\left(x_{e m}^{-1}\left(x_{i s}^{*}\right), K_{U}\right]$.

Determination of incumbent's strategic trigger

How would the incumbent determine the optimal preemption strategy by specifying its strategic trigger $x_{i s}^{*}$ to take certain value $z$ ? We show two numerical examples that demonstrate the tradeoff between the value of waiting $W_{i}\left(x \mid x_{t}^{\max }, z\right)$ and the value of holding the patent $V_{i}(x)-C$. In the first example, the incumbent does not benefit from delaying $x_{i s}^{*}$. As shown in Figure $1(\mathrm{a}), W_{i}\left(x \mid x_{t}^{\max }, z\right)$ is decreasing in $x$ while $V_{i}(x)-C$ is increasing in $x$. The following parameter values are used in performing the relevant calculations: $C=5, \pi_{i}^{-}=0.2, \pi_{e}=0.95, \pi_{i}^{+}=0.5, K_{e}=25, K_{i}=23, r=0.05, \mu=0.01$, $\sigma=0.3, K_{L}=15, K_{U}=50$. We choose the distribution function $G(K)$ to be the Pareto distribution

$$
G(K)=\frac{K^{-\alpha}-K_{L}^{-\alpha}}{K_{U}^{-\alpha}-K_{L}^{-\alpha}},
$$

where $\alpha=5$. In the plot, we observe $W_{i}\left(x \mid x_{t}^{\max }, z\right)<V_{i}(x)-C$ when $x$ is sufficiently close to the chosen value of strategic trigger $z$. The net difference is getting smaller in value when $x$ assumes the value $z-\delta, \delta$ is small and positive, when compared to that when $x$ equals to $z^{-}$. This indicates that it becomes worse for the incumbent to choose to delay $x_{i s}^{*}$ because it may occur that the value of waiting is lower than the value of holding the patent. In the second example, we illustrate that the incumbent may gain more by delaying $x_{i s}^{*}$. In Figure 1(b), we show a similar plot but now $W_{i}\left(x \mid x_{t}^{\max }, z\right)>V_{i}(x)-C$ for all values of $x$ below $z$. The following parameter values are used in the numerical calculations: $C=5, \pi_{i}^{-}=0.2, \pi_{e}=0.95, \pi_{i}^{+}=0.9, K_{e}=25$, $K_{i}=23, r=0.05, \mu=0.01, \sigma=0.3, K_{L}=25, K_{U}=50, G(K)$ is the Pareto distribution with $\alpha=5$. We also observe that the net difference $W_{i}\left(x \mid x_{t}^{\max }, z+\delta\right)-\left[V_{i}(x)-C\right]$ at $x=z$ assumes a higher positive value when we increase the strategic trigger from $z$ to $z+\delta, \delta$ is small and positive. Hence, it is advantageous for the incumbent to choose to delay $x_{i s}^{*}$ to the value $z+\delta$.

Apparently, the net difference between $W_{i}\left(x \mid x_{t}^{\max }, z\right)$ and $V_{i}(x)-C$ as $x \rightarrow z^{-}$is crucial in determining whether the given incumbent's choice of the strategic patent trigger $z$ is sub-optimal and another better choice for $x_{i s}^{*}$ should be sought. As $x \rightarrow z^{-}$, so does $x_{t}^{\max } \rightarrow z^{-}$, and accordingly we define 
the incumbent's preemption decision function $F(z)$ by

$$
F(z)=\lim _{x, x_{t}^{\max } \rightarrow z^{-}}\left\{W_{i}\left(x \mid x_{t}^{\max }, z\right)-\left[V_{i}(x)-C\right]\right\}, x_{e m}^{*}\left(K_{L}\right) \leq z \leq x_{e p}^{*}\left(K_{U}\right) .
$$

This function plays an important role in our analysis of the preemption strategies of the incumbent. Later, we establish that $F(z)<0$ for $z>x_{e m}^{*}\left(K_{L}\right)$ when $x_{i m}^{*}\left(K_{L}\right)<x_{e m}^{*}\left(K_{L}\right)$. On the other hand, $F(z)$ may change sign from being positive to negative or always stays positive for $z \in\left[x_{i m}^{*}\left(K_{L}\right), x_{e p}^{*}\left(K_{U}\right)\right]$ when $x_{i m}^{*}\left(K_{L}\right) \geq x_{e m}^{*}\left(K_{L}\right)$. In accordance to these properties on $F(z)$, when we consider the strategic interaction of preemption strategies between the two firms, it is instructive to consider the two separate cases: $x_{i m}^{*}\left(K_{L}\right)<x_{e m}^{*}\left(K_{L}\right)$ and $x_{i m}^{*}\left(K_{L}\right) \geq x_{e m}^{*}\left(K_{L}\right)$.

$\operatorname{Case}(i) x_{i m}^{*}\left(K_{L}\right)<x_{e m}^{*}\left(K_{L}\right)$

By examining the behavior of $F(z)$ for $x_{e m}^{*}\left(K_{L}\right) \leq z \leq x_{e p}^{*}\left(K_{U}\right)$, we would like to establish that the choice of $x_{i s}^{*}$ whose value equals or above $x_{e m}^{*}\left(K_{L}\right)$ is always non-optimal for the incumbent. When the incumbent chooses $x_{i s}^{*}$ to be lower than $x_{e m}^{*}\left(K_{L}\right)$, there is no preemptive threat from the entrant because the entrant never chooses to acquire the patent at a threshold below $x_{e m}^{*}\left(K_{L}\right)$. As a result, the incumbent is the winner in the patent race. The corresponding incumbent's strategic patent trigger and strategic claim value are summarized in Proposition 1.

Proposition 1 When $x_{i m}^{*}\left(K_{L}\right)<x_{e m}^{*}\left(K_{L}\right)$, the incumbent always wins the patent race. It chooses to exercise the patent option optimally at $x_{i p}^{*}$ if $x_{i p}^{*}<$ $x_{e m}^{*}\left(K_{L}\right)$ or epsilon-preempts the entrant at $x_{e m}^{*}\left(K_{L}\right)$ if otherwise. Therefore, the incumbent's strategic trigger is given by

$$
x_{i s}^{*}=\min \left\{x_{i p}^{*}, x_{e m}^{*}\left(K_{L}\right)-\varepsilon\right\},
$$

where $\varepsilon$ is an infinitesimally small positive quantity. The corresponding incumbent's strategic claim value prior to acquisition of the patent at the profit flow rate level $x, x<x_{i s}^{*}$, is given by

$$
\left[V_{i}\left(x_{i s}^{*}\right)-C\right]\left(\frac{x}{x_{i s}^{*}}\right)^{\beta} .
$$

The proof of Proposition 1 is presented in Appendix A. In summary, it is optimal for the incumbent to delay $x_{i s}^{*}$ until the minimum of $x_{i p}^{*}$ and 
$x_{e m}^{*}\left(K_{L}\right)-\varepsilon$. The incumbent wins without facing preemptive threat from the entrant. The incumbent's strategy of delaying $x_{i s}^{*}$ beyond $x_{e m}^{*}\left(K_{L}\right)$ is seen to be sub-optimal. This also leads to a finite probability of being preempted by the entrant. To relate the incumbent's strategic patent strategies to the preemption decision function $F(z)$, the incumbent should not choose $x_{i s}^{*}$ to assume the value $z$ when $F(z)$ becomes negative. When $x_{i m}^{*}\left(K_{L}\right)<x_{e m}^{*}\left(K_{L}\right)$, it is shown in Appendix A that $F(z)<0$ for $z>x_{e m}^{*}\left(K_{L}\right)$. In the numerical example shown in Figure 2(a), we observe that $F(z)$ is decreasing in $z$ and $F(z)=0$ at $z=x_{e m}^{*}\left(K_{L}\right)$. The numerical calculations for Figure 2(a) employ the following set of parameter values: $C=5, \pi_{i}^{-}=0.2, \pi_{e}=0.9, \pi_{i}^{+}=0.7$, $K_{e}=25, K_{i}=23, r=0.05, \mu=0.01, \sigma=0.3, K_{L}=20, K_{U}=60, G(K)$ is the Pareto distribution with $\alpha=5$. Indeed, by taking $x_{i s}^{*}=x_{e m}^{*}\left(K_{L}\right)$ in the integral in Eq.(A.1) (see Appendix A), we obtain $F\left(x_{e m}^{*}\left(K_{L}\right)\right)=0$.

Case (ii): $x_{i m}^{*}\left(K_{L}\right) \geq x_{e m}^{*}\left(K_{L}\right)$

The determination of the patent race's winner becomes more complicated when $x_{i m}^{*}\left(K_{L}\right) \geq x_{e m}^{*}\left(K_{L}\right)$. In this case, the incumbent always faces with a positive probability of being preempted since the lower bound of $x_{i s}^{*}$ is higher than or equal to the lower bound of $x_{e s}^{*}$. The choice of a higher strategic patent trigger $x_{i s}^{*}$ by the incumbent means a higher real option value of waiting but facing a higher risk of being preempted.

When $x_{i m}^{*}\left(K_{L}\right) \geq x_{e m}^{*}\left(K_{L}\right)$, we establish in the proof of Proposition 2 that there exists a critical threshold $z^{*}$ whose value is above $x_{i m}^{*}\left(K_{L}\right)$ such that the incumbent breaks even with respect to the real option value of waiting and expected preempted loss. This breakeven trigger $z^{*}$ satisfies $F\left(z^{*}\right)=0$. It can be shown that the incumbent can only choose to acquire the patent strategically at $z^{*}$ only if it has not been preempted at a lower threshold by the entrant. When $z^{*} \geq x_{e m}^{*}\left(K_{U}\right)$, the incumbent can never win since even the most cost-inefficient entrant would have preempted the incumbent. The more interesting case corresponds to $z^{*}<x_{e m}^{*}\left(K_{U}\right)$. Since the entrant knows its true commercialization cost $K_{e}$, it has the full knowledge of $x_{e m}^{*}\left(K_{e}\right)$, $x_{e p}^{*}\left(K_{e}\right)$ and $z^{*}$. The winner of the patent race is decided by the relative ordering of $z^{*}, x_{e m}^{*}\left(K_{e}\right)$ and $x_{e p}^{*}\left(K_{e}\right)$. The determination of the patent race's winner and the corresponding equilibrium preemption triggers are summarized in Proposition 2.

Proposition 2 When $x_{i m}^{*}\left(K_{L}\right) \geq x_{e m}^{*}\left(K_{L}\right)$, the entrant always wins in the patent race and chooses to exercise the patent option optimally at $x_{e p}^{*}\left(K_{e}\right)$ if 
$F(z)>0$ for $z \in\left[x_{i m}^{*}\left(K_{L}\right), x_{e p}^{*}\left(K_{U}\right)\right]$. If $F(z)$ has a root $z^{*}$ that lies within $\left[x_{i m}^{*}\left(K_{L}\right), x_{e p}^{*}\left(K_{U}\right)\right]$, then the winner in the patent race is determined by the relative ordering of $z^{*}$ and the trigger thresholds $x_{e m}^{*}\left(K_{e}\right)$ and $x_{e p}^{*}\left(K_{e}\right)$.

(a) $z^{*}>x_{e m}^{*}\left(K_{U}\right)$

The entrant wins the patent race surely and it chooses to exercise the patent option at $\min \left\{z^{*}-\varepsilon, x_{e p}^{*}\left(K_{e}\right)\right\}$.

(b) $z^{*} \leq x_{e m}^{*}\left(K_{U}\right)$

We consider the following three separate cases:

(i) $z^{*}<x_{e m}^{*}\left(K_{e}\right)<x_{e p}^{*}\left(K_{e}\right)$

The incumbent wins the patent race and it chooses to preempt strategically at the break-even trigger $z^{*}$, which is below $x_{e m}^{*}\left(K_{e}\right)$ at which the entrant breaks even.

(ii) $x_{e m}^{*}\left(K_{e}\right)<z^{*} \leq x_{e p}^{*}\left(K_{e}\right)$

The entrant wins the patent race and it chooses to epsilon-preempt its opponent at $z^{*}-\varepsilon$ strategically.

(iii) $x_{e m}^{*}\left(K_{e}\right)<x_{e p}^{*}\left(K_{e}\right)<z^{*}$

The entrant wins the patent race and it chooses to exercise the patent option optimally at $x_{e p}^{*}$ without preemptive threat from the incumbent.

In the unlikely event that $z^{*}=x_{e m}^{*}\left(K_{e}\right)$, both firms rush to exercise the patent option at this common trigger and each has $50 \%$ chance of winning.

The proof of Proposition 2 is presented in Appendix B. In the numerical example shown in Figure 2(b), we observe that when $x_{i m}^{*}\left(K_{L}\right) \geq x_{e m}^{*}\left(K_{L}\right)$, $F(z)$ is monotonically decreasing in $z$ with $F\left(x_{e m}^{*}\left(K_{L}\right)\right)>0$ and $F(z)$ has a root $z^{*}$, where $z^{*}>x_{i m}^{*}\left(K_{L}\right)$. The parameter values used in the numerical calculations for Figure 2(b) are: $C=5, \pi_{i}^{-}=0.2, \pi_{e}=0.9, \pi_{i}^{+}=0.7$, $K_{e}=25, K_{i}=23, r=0.05, \mu=0.01, \sigma=0.3, K_{L}=15, K_{U}=60, G(K)$ is the Pareto distribution with $\alpha=5$.

\section{Impact of information asymmetry on pre- emption strategies and sleeping patent}

In this section, we would like to investigate how information asymmetry on the entrant's commercialization cost $K_{e}$ may affect the preemption strategies 
of the two firms. For notational convenience, we let $x_{j s}^{a s y}$ and $x_{j s}^{c o m p}$ denote the preemption trigger of Firm $j, j=i, e$, under asymmetric information and complete information, respectively. We would like to address the following queries:

1. Is it possible that there is a swap of the winner of the patent race from the complete information model to the asymmetric information model?

2. Given the informationally disadvantaged status, one may envision that the incumbent may respond more aggressively. Does this always lead to $x_{i s}^{a s y} \leq x_{i s}^{c o m p}$ ? Do we have a similar relative ordering that holds between $x_{e s}^{a s y}$ and $x_{e s}^{c o m p}$ ?

Under complete information, recall that the key factor that determines the winner is the relative ordering of the Marshallian triggers of the two firms: $x_{i m}^{*}\left(K_{e}\right)$ and $x_{e m}^{*}\left(K_{e}\right)$. Here, we emphasize the dependence of the Marshallian trigger of the two firms on the true entrant's commercialization cost $K_{e}$. While the firm with the lower Marshallian trigger is the winner of the patent race under complete information (Leung and Kwok, 2010), the criteria that determine the patent race's winner become more complicated under information asymmetry (see Propositions 1 and 2). We analyze the impact of asymmetric information on preemption triggers of the two firms with regard to $x_{i m}^{*}\left(K_{e}\right)<x_{e m}^{*}\left(K_{e}\right)$ or otherwise.

Case (i): $x_{i m}^{*}\left(K_{e}\right)<x_{e m}^{*}\left(K_{e}\right)$

When $x_{i m}^{*}\left(K_{e}\right)<x_{e m}^{*}\left(K_{e}\right)$, the incumbent is the winner under complete information in which the incumbent either epsilon-preempts the entrant at $x_{e m}^{*}\left(K_{e}\right)-\varepsilon$ or exercises the patent option optimally at the non-strategic patent trigger $x_{i p}^{*}$. In summary, we have

$$
x_{i s}^{c o m p}=\min \left\{x_{e m}^{*}\left(K_{e}\right)-\varepsilon, x_{i p}^{*}\right\} .
$$

Under information asymmetry, we have to consider either $x_{i m}^{*}\left(K_{L}\right)<x_{e m}^{*}\left(K_{L}\right)$ or otherwise. According to Proposition 1, when $x_{i m}^{*}\left(K_{L}\right)<x_{e m}^{*}\left(K_{L}\right)$, we have

$$
x_{i s}^{a s y}=\min \left\{x_{e m}^{*}\left(K_{L}\right)-\varepsilon, x_{i p}^{*}\right\} .
$$

Since $x_{e m}^{*}(K)$ is an increasing function of $K, K \in\left[K_{L}, K_{U}\right]$, so we conclude that $x_{i s}^{a s y} \leq x_{i s}^{c o m p}$. 
We also consider the possibility that $x_{i m}^{*}\left(K_{L}\right) \geq x_{e m}^{*}\left(K_{L}\right)$ [though this is under the assumption that $\left.x_{i m}^{*}\left(K_{e}\right)<x_{e m}^{*}\left(K_{e}\right)\right]$. In this case, the incumbent wins the patent race only if $z^{*}<x_{e m}^{*}\left(K_{e}\right)$ (see Proposition 2) and $x_{i s}^{a s y}=z^{*}$. In Appendix $\mathrm{C}$, we establish the following result:

$$
z^{*}<x_{i m}^{*}\left(K_{e}\right) .
$$

Accordingly, we obtain

$$
x_{i s}^{a s y}=z^{*}<x_{i m}^{*}\left(K_{e}\right) \leq \min \left\{x_{e m}^{*}\left(K_{e}\right)-\varepsilon, x_{i p}^{*}\right\}=x_{i s}^{c o m p} .
$$

We conclude that whenever the incumbent is the winner in the patent race, we always have $x_{i s}^{a s y} \leq x_{i s}^{c o m p}$. Equality of $x_{i s}^{a s y}$ and $x_{i s}^{c o m p}$ may occur under various scenarios. For illustration, two of these possible scenarios are listed below:

(i) $x_{i s}^{a s y}=x_{i s}^{\text {comp }}=x_{i p}^{*}$, assuming $x_{i p}^{*}<x_{e m}\left(K_{L}\right)$;

(ii) $x_{i s}^{a s y}=x_{i s}^{c o m p}=x_{e m}^{*}\left(K_{e}\right)-\varepsilon$, assuming $x_{e m}^{*}\left(K_{e}\right) \leq x_{i p}^{*}$, and $K_{e}$ happens to take the lowest value $K_{L}$.

Case (ii): $x_{e m}^{*}\left(K_{e}\right)<x_{i m}^{*}\left(K_{e}\right)$

When $x_{e m}^{*}\left(K_{e}\right)<x_{i m}^{*}\left(K_{e}\right)$, the entrant is the winner under complete information whose strategic patent trigger is seen to be

$$
x_{e s}^{c o m p}=\min \left\{x_{i m}^{*}\left(K_{e}\right)-\varepsilon, x_{e p}^{*}\right\} .
$$

We observe from Proposition 2 that there is a critical break-even threshold $z^{*}$ for the incumbent such that the incumbent wins the patent race if $z^{*}<$ $x_{e m}^{*}\left(K_{e}\right)$. If the above scenario occurs, then we have $z^{*}<x_{i m}^{*}\left(K_{e}\right)$ since $x_{i m}^{*}\left(K_{e}\right)>x_{e m}^{*}\left(K_{e}\right)$. Consequently, this gives

$$
V_{i}\left(z^{*}\right)-C<L_{i}\left(z^{*} ; K_{e}\right) .
$$

The expression on the left hand side gives the real option value to the incumbent if the incumbent acquires the patent at $z^{*}$, which is seen to be less than the expected loss if the entrant exercises preemption at $z^{*}$ instead. Thus an inefficient outcome to the incumbent is resulted when the incumbent chooses the strategic patent trigger to be $z^{*}$ with regard to its informationally disadvantaged status. This aggressive action of the incumbent, however, leads to 
a swapping of the winner in the patent race from the entrant under complete information to the incumbent under information asymmetry. It is a lose-lose scenario for both firms.

For the other case $z^{*}>x_{e m}\left(K_{e}\right)$, Proposition 2 states that the entrant wins the patent race either by taking epsilon-preemption at $z^{*}-\varepsilon$ or optimal entry at $x_{e p}^{*}\left(K_{e}\right)$. In this case, the entrant retains its winner status under information asymmetry. The entrant's strategic patent trigger under information asymmetry can be higher or lower than that under complete information, depending on the relative magnitude of $z^{*}$ and $x_{i m}^{*}\left(K_{e}\right)$. Given $x_{e m}^{*}\left(K_{e}\right)<\min \left\{x_{i m}^{*}\left(K_{e}\right), z^{*}\right\}$, we deduce that $x_{e s}^{a s y}<x_{e s}^{c o m p}$ if and only if (i) $z^{*}<x_{i m}^{*}\left(K_{e}\right) \leq x_{e p}^{*}\left(K_{e}\right)$, or (ii) $z^{*} \leq x_{e p}^{*}\left(K_{e}\right)<x_{i m}^{*}\left(K_{e}\right)$.

We illustrate the above observations of the two firms' preemption strategies and potential swapping of the patent race's winner by plotting the incumbent's breakeven threshold $z^{*}$ against $K_{L}$ in Figure 3. In our sample calculations, we choose the distribution function $G(K)$ to be the Pareto distribution with $\alpha=5$. The other parameter values used in the calculations are: $r=0.05, \mu=0.03, C=5, \sigma=0.3, \pi_{i}^{+}=0.7, \pi_{i}^{-}=0.2, \pi_{e}=0.95$, $K_{i}=23, K_{e}=25$ and $K_{U}=40$. In this numerical example, the parameter values have been chosen such that $x_{e m}^{*}\left(K_{e}\right)<x_{i m}^{*}\left(K_{e}\right)$ so that the entrant is the winner under complete information. We also have $x_{i m}^{*}\left(K_{e}\right)<x_{e p}^{*}\left(K_{e}\right)$ so that when the entrant is the winner it would win by strategic epsilonpreemption but not optimal entry at $x_{e p}^{*}\left(K_{e}\right)$.

The plot in Figure 3 illustrates that the incumbent's belief on the lowest value $K_{L}$ of the entrant's commercialization cost can have strong influence on the determination of the patent race's winner and the preemption strategies of the competing firms. When $K_{L}$ is sufficiently low, the incumbent responds more aggressively to its informationally disadvantaged status such that $z^{*}$ may be less than $x_{e m}^{*}\left(K_{e}\right)$. In this case, the incumbent wins the patent race under information asymmetry though this is a lose-lose scenario for both firms. When $K_{L}$ assumes some critical value $K^{*}$, we have $z^{*}=x_{e m}^{*}\left(K_{e}\right)$. When $K_{L}>K^{*}$, the entrant wins under information asymmetry and it chooses to epsilon-preempt the incumbent at $z^{*}-\varepsilon$. More precisely, for some $K^{* *}$ and when $K^{*}<K_{L}<K^{* *}$, we have $x_{e s}^{a s y}<x_{e s}^{c o m p}$; while when $K_{L}>K^{* *}$, we have $x_{e s}^{a s y}>x_{e s}^{c o m p}$ (see Figure 3 ). In the latter case, the entrant delays its act of strategic epsilon-preemption so it receives the benefit of gaining more real option value of investment. In summary, the entrant may become the loser in the patent race under information asymmetry. Also, the entrant's real option value of investment may be undermined or enhanced, depending 
on whether $K_{e}$ is biased low or biased high, respectively.

We also explore the dependence of the incumbent's breakeven threshold $z^{*}$ and Marshallian triggers on the revenue flow volatility $\sigma$, a numerical example of which is shown in Figure 4. The parameter values used in the numerical calculations for Figure 4 are: $C=5, \pi_{i}^{-}=0.2, \pi_{e}=0.95, \pi_{i}^{+}=0.7, K_{e}=25$, $K_{i}=23, r=0.05, \mu=0.01, K_{L}=20, K_{U}=50, G(K)$ is the Pareto distribution with $\alpha=5$. When $\sigma$ is sufficiently low (below some critical value $\left.\sigma^{*}\right)$, we have $z^{*}<x_{e m}^{*}\left(K_{e}\right)<x_{i m}^{*}\left(K_{e}\right)$. Under complete informaiton, the entrant is the winner since $x_{e m}^{*}\left(K_{e}\right)<x_{i m}^{*}\left(K_{e}\right)$. However, under information asymmetry, the incumbent becomes the winner with $x_{i s}^{a s y}=z^{*}$ since $z^{*}<$ $x_{e m}^{*}\left(K_{e}\right)$. This results in a swap of winner in the patent race as the incumbent acts aggressively and preempts the entrant strategically at the threshold $z^{*}$. On the other hand, when $\sigma$ is sufficiently high (above some critical value $\left.\sigma^{* *}\right)$, we have $x_{e m}^{*}\left(K_{e}\right)<x_{i m}^{*}\left(K_{e}\right)<z^{*}$. The entrant remains to be the winner when complete information is changed to information asymmetry. Note that $x_{e s}^{a s y}=z^{*}-\varepsilon$ while $x_{e s}^{c o m p}=x_{i m}^{*}\left(K_{e}\right)-\varepsilon$ so $x_{e s}^{c o m p}<x_{e s}^{a s y}$. The entrant's strategic patent trigger is delayed under information asymmetry, thus resulting in some gain in the entrant's real option value of the patent right. For an intermediate level of $\sigma$ where $\sigma^{*}<\sigma<\sigma^{* *}$, we have $x_{e m}^{*}\left(K_{e}\right)<$ $z^{*}<x_{i m}^{*}\left(K_{e}\right)$. In this case, the entrant remains to be the winner under information asymmetry with $x_{e s}^{a s y}<x_{e s}^{c o m p}$. The entrant is forced to exercise epsilon-preemption at a lower threshold $z^{*}-\varepsilon$ under information asymmetry due to an anticipation of the aggressive response of the incumbent.

\section{Sleeping patent}

Sleeping patent occurs when the patent is acquired strategically by epsilonpreemption while the corresponding strategic patent trigger is below the winner's commercialization trigger, that is, $x_{w s}^{*}<x_{w c}^{*}$. Here, the subscript $w$ denotes the winner in the patent race.

When the incumbent is the winner under complete information, Proposition 2 states that the incumbent remains to be the winner under information asymmetry and $x_{i s}^{a s y} \leq x_{i s}^{\text {comp }}$. Suppose sleeping patent occurs under complete information for the incumbent, the same phenomena persists under information asymmetry. Also, the expected duration of sleeping patent is lengthened or remains the same under information asymmetry since $x_{i c}^{*}-x_{i s}^{a s y} \geq$ $x_{i c}^{*}-x_{i s}^{c o m p}$, where $x_{i c}^{*}$ denotes the incumbent's commercialization trigger.

For the other case where the winner is the entrant under complete information, it has been shown that the entrant may lose its winner status when 
$z^{*}<x_{e m}^{*}\left(K_{e}\right)$. In this case, if the entrant lets the patent sleep under complete information, then the occurrence of sleeping patent under information asymmetry depends on the relative ordering of incumbent's strategic triggers instead of that of entrant. When the entrant retains its winner status under information asymmetry, as $x_{e s}^{a s y}$ can be below or above $x_{e s}^{\text {comp }}$, the corresponding expected duration of sleeping patent (if exists) is lengthened or shortened, respectively.

Finally, we would like to consider the interesting though unlikely scenario where $x_{i m}^{*}\left(K_{e}\right)=x_{e m}^{*}\left(K_{e}\right)$. In this case, both firms rush to acquire the patent at this common trigger with $50 \%$ chance of winning under complete information. As $K_{L}<K_{e}$, so $x_{i m}^{*}\left(K_{L}\right)<x_{i m}^{*}\left(K_{e}\right)=x_{e m}^{*}\left(K_{e}\right)$. Based on the above discussions, we deduce that the incumbent is sure to be the winner under information asymmetry and $x_{i s}^{*}=z^{*}<x_{e m}^{*}\left(K_{e}\right)$. Suppose sleeping patent occurs under complete information, that is, $x_{i m}^{*}\left(K_{e}\right)=x_{e m}^{*}\left(K_{e}\right)<$ $\min \left\{x_{i c}^{*}, x_{e c}^{*}\right\}$, then the expected duration of sleeping patent is lengthened under information asymmetry. On the other hand, suppose $x_{i m}^{*}\left(K_{e}\right)=$ $x_{e m}^{*}\left(K_{e}\right) \geq \max \left\{x_{i c}^{*}, x_{e c}^{*}\right\}$, then there is no sleeping patent occurring under complete information. With potential lowering of $x_{i s}^{a s y}$, the incumbent would let the patent sleep if $z^{*}<x_{i c}^{*}$. By applying a similar analysis for other cases of relative ordering of $x_{i c}^{*}, x_{e c}^{*}$ and $x_{i m}^{*}\left(K_{e}\right)$, the corresponding potential change in sleeping patent from complete information to information asymmetry can be obtained.

\section{Conclusion}

Our two-stage patent-investment model examines the real options game in patenting and commercialization of a product under preemptive competition and revenue flow uncertainty. In particular, the present study sheds new insight on the understanding of the importance of cost information asymmetry on the preemption triggers in patent races. We found that the incumbent tends to act aggressively in response to its informationally disadvantaged status. As a result, when the incumbent is the winner in the patent race under complete information, it remains to be the winner under information asymmetry. However, it may occur that the winner status of the entrant under complete information may be swapped such that the entrant becomes the loser in the game under information asymmetry. The reversal of the game winner from complete information to information asymmetry is not observed 
in Hsu-Lambrecht's one-stage patent race model. Our study shows that the strategic patent trigger of the winning incumbent is in most cases lowered or stays at the same value (good news for the incumbent). However, the preemption patent trigger of the winning entrant may be lowered or increased, depending on whether the incumbent's belief on the entrant's commercialization cost is biased low or high, respectively. When the incumbent is the winner in the patent race, the real option values of investment of both firms are in general lowered. When the entrant is the winner, the real option values of both firms may be lowered or increased, depending on the incumbent's belief on the entrant's cost. In general, the duration of a sleeping patent is lengthened under information asymmetry due to the aggressive response of the incumbent. Under certain conditions, the expected duration of a sleeping patent may be shortened. This occurs when under information asymmetry the entrant has the luxury of delaying its strategic patent trigger to a higher threshold value.

\section{References}

[1] Gilbert, R.J., Newbery, D.M.G., 1982. Preemptive patenting and the persistence of monopoly, American Economic Review, 72(3), 514-526.

[2] Harris, C., Vickers, J., 1985. Patent races and the persistence of monopoly, Journal of Industrial Economics, 33, 461-481.

[3] Hsu, Y.W., Lambrecht, B.M., 2007. Preemptive patenting under uncertainty and asymmetric information, Annals of Operations Research, 151(1), 5-28.

[4] Lambrecht, B., 2000. Strategic sequential investments and sleeping patents, in Project Flexibility, Agent and Competition: New Developments in the Theory and Application of Real Options, edited by Brennan, M.J. and Trigeorgis, L., Oxford University Press, Oxford.

[5] Lambrecht, B., Perraudin, W., 2003. Real options and preemption under complete information, Journal of Economic Dynamics and Control, 27, 619-643. 
[6] Leung, C.M., Kwok, Y.K., 2010. Real options game analysis of sleeping patents, Working paper of the Hong Kong University of Science and Technology.

[7] Sereno, L., 2008. Real options and economic valuation of patents, Working paper of University of Bologna.

[8] Thijssen, J.J.J., Huisman K.J.M., Kort P.M., 2006. The effects of information on strategic investment and welfare, Economic Theory, 28, 399424.

[9] Zhu, K., Weyant, J., 2003. Strategic decisions of new technology adoption under asymmetric information: a game theoretic model, Decision Sciences, 34(4), 643-675. 


\section{Appendix A - Proof of Proposition 1}

The incumbent's strategy of choosing $x_{i s}^{*}>x_{e m}^{*}\left(K_{L}\right)$ is seen to be sub-optimal if we can establish that the immediate exercise payoff function $V_{i}(x)-C$ at $x_{t}$ slightly below $x_{i s}^{*}$ becomes higher than the incumbent's waiting value $W_{i}\left(x \mid x_{t}^{\max }, x_{i s}^{*}\right)$ when the incumbent chooses to wait until $x_{t}$ reaches $x_{i s}^{*}$ from below. By letting $x$ and $x_{t}^{\max }$ approach $x_{i s}^{*}$ from below, we obtain [see Eqs.(3.8) and (3.9)]

$$
\begin{gathered}
\lim _{x, x_{t}^{\max } \rightarrow x_{i s}^{-}}\left\{W_{i}\left(x \mid x_{t}^{\max }, x_{i s}^{*}\right)-\left[V_{i}(x)-C\right]\right\} \\
=\int_{K_{L}}^{x_{e m}^{-1}\left(x_{i s}^{*}\right)}\left\{L_{i}\left(x_{i s}^{*} ; K\right)-\left[V_{i}\left(x_{i s}^{*}\right)-C\right]\right\} d \bar{G}(K)<0 .
\end{gathered}
$$

The last inequality is established by observing

$$
x_{i s}^{*}=x_{e m}^{*}\left(x_{e m}^{-1}\left(x_{i s}^{*}\right)\right)>x_{i m}^{*}\left(x_{e m}^{-1}\left(x_{i s}^{*}\right)\right) \geq x_{i m}^{*}(K)
$$

for $K \in\left[K_{L}, x_{e m}^{-1}\left(x_{i s}^{*}\right)\right]$ so that

$$
L_{i}\left(x_{i s}^{*} ; K\right)<V_{i}\left(x_{i s}^{*}\right)-C \text { for } K_{L} \leq K \leq x_{e m}^{-1}\left(x_{i s}^{*}\right) .
$$

Therefore, we conclude that it is sub-optimal for the incumbent to choose $x_{i s}^{*}$ to be above $x_{e m}^{*}\left(K_{L}\right)$ since immediate exercise at a threshold slightly below $x_{i s}^{*}$ results in higher real option value.

On the other hand, the incumbent faces no preemptive threat when $x_{i s}^{*}<$ $x_{e m}^{*}\left(K_{L}\right)$. Apparently, allowing a finite probability of being preempted by the entrant leads to a sub-optimal strategy, so the upper bound of $x_{i s}^{*}$ is seen to be $x_{e m}^{*}\left(K_{L}\right)$. When $x_{i s}^{*}$ is delayed but does not go beyond $x_{e m}^{*}\left(K_{L}\right)$, then there always exists more gain in the option value of waiting while facing no potential preemptive loss. In equilibrium, the incumbent chooses to exercise the patent option optimally at $x_{i p}^{*}$ if $x_{i p}^{*}<x_{e m}^{*}\left(K_{L}\right)$ or epsilon-preempts its opponent strategically at $x_{e m}^{*}\left(K_{L}\right)-\varepsilon$ if otherwise.

When $x_{i m}^{*}\left(K_{L}\right)<x_{e m}^{*}\left(K_{L}\right)$, the incumbent then always wins the patent race. The strategic patent trigger is given by

$$
x_{i s}^{*}=\min \left\{x_{i p}^{*}, x_{e m}^{*}\left(K_{L}\right)-\varepsilon\right\} .
$$

The strategic claim value at $x_{t}=x$, where $x<x_{i s}^{*}$, is seen to be

$$
\left[V_{i}\left(x_{i s}^{*}\right)-C\right]\left(\frac{x}{x_{i s}^{*}}\right)^{\beta} \text {. }
$$




\section{Appendix B - Proof of Proposition 2}

The incumbent's preemption decision function $F(z)$ defined in Eq. (3.10) is seen to be continuous and decreasing for $z \in\left[x_{i m}^{*}\left(K_{L}\right), x_{e p}^{*}\left(K_{U}\right)\right]$ since the value of waiting decreases with increasing strategic patent trigger. Note that for $x_{i m}\left(K_{L}\right)>x_{e m}\left(K_{L}\right)$, we have

$$
F\left(x_{i m}^{*}\left(K_{L}\right)\right)>0 .
$$

First, we consider the case where $F(z)>0$ for $z \in\left[x_{i m}^{*}\left(K_{L}\right), x_{e p}^{*}\left(K_{U}\right)\right]$. We claim that the incumbent should not choose $x_{i s}^{*}$ to lie within $x_{i m}^{*}\left(K_{L}\right)$ and $x_{e p}^{*}\left(K_{U}\right)$. It suffices to show that it is sub-optimal to choose $x_{i s}^{*} \leq x_{e p}^{*}\left(K_{U}\right)$. We would like to establish that the immediate exercise payoff function $V_{i}(x)-$ $C$ at $x=x_{i s}^{*}$ is always less than the waiting value $W_{i}\left(x \mid x_{t}^{\max }, x_{i s}^{*}+\delta\right)$ when the incumbent chooses to wait until $x_{t}$ reaches $x_{i s}^{*}+\delta$ from below for some $\delta$ that is small and positive. By letting $x$ and $x_{t}^{\max }$ approach $x_{i s}^{*}$ from below, we obtain

$$
\begin{aligned}
& \lim _{x_{t}, x_{t}^{\max } \rightarrow x_{i s}^{-}}\left\{W_{i}\left(x \mid x_{t}^{\max }, x_{i s}^{*}\right)-\left[V_{i}(x)-C\right]\right\} \\
= & \int_{\max \left\{K_{L}, x_{e p}^{-1}\left(x_{t}^{\max }\right)\right\}}^{x_{e m}^{-1}\left(x_{i s}^{*}\right)}\left\{L_{i}\left(x_{i s}^{*} ; K\right)-\left[V_{i}\left(x_{i s}^{*}\right)-C\right]\right\} d \bar{G}(K)>0 .
\end{aligned}
$$

Using the continuity of $W_{i}\left(x \mid x_{t}^{\max }, x_{i s}^{*}\right)$, there exists a small quantity $\delta>0$ such that

$$
\lim _{x_{t}, x_{t}^{\max } \rightarrow x_{i s}^{-}}\left\{W_{i}\left(x \mid x_{t}^{\max }, x_{i s}^{*}+\delta\right)-\left[V_{i}(x)-C\right]\right\}>0 .
$$

So the incumbent finds itself to be better off when it chooses by delaying its strategic patent trigger to a slightly higher threshold though it faces a higher probability of being preempted. As a result, any strategic patent trigger $x_{i s}^{*} \leq x_{e p}^{*}\left(K_{U}\right)$ is sub-optimal for the incumbent. On the other hand, it is not feasible for the incumbent to choose the patent trigger to be above $x_{e p}^{*}\left(K_{U}\right)$. It is clear that the entrant firm would have preempted the incumbent already and thus the entrant is winner in the patent race. Indeed, the entrant exercises the patent option optimally at $x_{e p}^{*}\left(K_{e}\right)$.

Next, we consider the case where there exists $z^{*} \in\left(x_{i m}^{*}\left(K_{L}\right), x_{e p}^{*}\left(K_{U}\right)\right)$ such that

$$
F\left(z^{*}\right)=0
$$


Since $F(z)$ is decreasing in the corresponding domain, so $F(z)>0$ for $z<z^{*}$ and $F(z)<0$ for $z>z^{*}$. Suppose the incumbent chooses $x_{i s}^{*}<z^{*}$, then

$$
F\left(x_{i s}^{*}\right)=\int_{\max \left\{K_{L}, x_{e p}^{-1}\left(x_{t}^{\max }\right)\right\}}^{x_{e m}^{-1}\left(x_{i s}^{*}\right)}\left\{L_{i}\left(x_{i s}^{*}, K\right)-\left[V_{i}\left(x_{i s}^{*}\right)-C\right]\right\} d \bar{G}(K)>0 .
$$

By continuity, there exists a small quantity $\delta>0$ such that

$$
W_{i}\left(x_{i s}^{*} \mid x_{i s}^{*}, x_{i s}^{*}+\delta\right)-\left[V_{i}\left(x_{i s}^{*}\right)-C\right]>0 .
$$

So the incumbent finds itself better off by delaying its strategic patent trigger though it faces a higher probability of being preempted. Therefore, any choice of the strategic patent trigger below $z^{*}$ is not optimal.

On the other hand, if the incumbent chooses $x_{i s}^{*}>z^{*}$, then

$$
F\left(x_{i s}^{*}\right)=\int_{\max \left\{K_{L}, x_{e p}^{-1}\left(x_{t}^{\max }\right)\right\}}^{x_{e m}^{-1}\left(x_{i s}^{*}\right)}\left\{L_{i}\left(x_{i s}^{*} ; K\right)-\left[V_{i}\left(x_{i s}^{*}\right)-C\right]\right\} d \bar{G}(K)<0 .
$$

In a similar manner, we deduce that there exists a small quantity $\delta>0$ such that

$$
W_{i}\left(x_{i s}^{*}-\delta \mid x_{i s}^{*}-\delta, x_{i s}^{*}\right)-\left[V_{i}\left(x_{i s}^{*}-\delta\right)-C\right]<0 .
$$

This indicates that it is now better for the incumbent to lower the choice of its strategic patent trigger.

Finally, by observing the value matching property, where

$$
F\left(z^{*}\right)=\int_{\max \left\{K_{L}, x_{e p}^{-1}\left(x_{t}^{\max }\right)\right\}}^{x_{e m}^{-1}\left(z^{*}\right)}\left\{L_{i}\left(z^{*} ; K\right)-\left[V_{i}\left(z^{*}\right)-C\right]\right\} d \bar{G}(K)=0,
$$

we can deduce that

$$
W_{i}\left(x, x_{t}^{\max } \mid z^{*}\right)>V_{i}(x)-C \text { for } x<z^{*} .
$$

This implies that the incumbent should never exercise the patent option at any trigger level lower than $z^{*}$. Also, we can deduce

$$
W_{i}\left(z^{*}, x_{t}^{\max } \mid z\right)<V_{i}\left(z^{*}\right)-C \text { for } z>z^{*},
$$

which implies that the incumbent should never delay its strategic patent trigger at any level higher than $z^{*}$. As a result, $x_{i s}^{*}=z^{*}$ is the equilibrium trigger. 
Recall that the entrant has full information on the incumbent's commercialization cost and hence the entrant knows $x_{i s}^{*}$. If $z^{*}>x_{e m}^{*}\left(K_{U}\right)$, it is clear that the entrant always preempts the incumbent so it is the winner of the patent race. Also the entrant chooses to exercise the patent option either strategically at $z^{*}-\varepsilon$ if $z^{*} \leq x_{e p}^{*}\left(K_{e}\right)$ or optimally at $x_{e p}^{*}\left(K_{e}\right)$ if otherwise. If $z^{*} \leq x_{e m}^{*}\left(K_{U}\right)$, the entrant always preempts the incumbent if $x_{i s}^{*} \geq x_{e m}^{*}\left(K_{e}\right)$ and will not preempt if otherwise. Given that $x_{i s}^{*}=z^{*}$, we can deduce that the incumbent can acquire the patent at $z^{*}$ successfully and it wins the patent race if $z^{*}<x_{e m}^{*}\left(K_{e}\right)$. Otherwise, if $z^{*}>x_{e m}^{*}\left(K_{e}\right)$, the entrant either epsilonpreempts the incumbent at $z^{*}-\varepsilon$ if $z^{*} \leq x_{e p}^{*}\left(K_{e}\right)$ or optimally acquires the patent at $x_{e p}^{*}$ if $z^{*}>x_{e p}^{*}\left(K_{e}\right)$. In this case, the winner is the entrant. 
Appendix C - Proof of $z^{*}<x_{i m}^{*}\left(K_{e}\right)$ under $x_{i m}^{*}\left(K_{e}\right)<x_{e m}^{*}\left(K_{e}\right)$ and $x_{i m}^{*}\left(K_{L}\right) \geq x_{e m}^{*}\left(K_{L}\right)$

First, we establish the following property on the relative ordering of $x_{i m}^{*}(K)$ and $x_{e m}^{*}(K)$ as $K$ assumes value ranging from 0 to infinity. There exists a critical $\bar{K} \in[0, \infty)$ such that

$$
x_{i m}^{*}(\bar{K})=x_{e m}^{*}(\bar{K})
$$

Also, we observe

$$
\begin{aligned}
& x_{i m}^{*}(K)>x_{e m}^{*}(K) \text { for } K<\bar{K} ; \\
& x_{i m}^{*}(K)<x_{e m}^{*}(K) \text { for } K>\bar{K} .
\end{aligned}
$$

The above results follow directly from Proposition 3 in Leung and Kwok (2009).

For convenience, we write $y^{*}=x_{i m}^{*}(\bar{K})=x_{e m}^{*}(\bar{K})$. In the next step, we would like to establish $z^{*} \leq y^{*}$. Using the above property, we can deduce

$$
y^{*}=x_{e m}^{*}\left(x_{e m}^{-1}\left(y^{*}\right)\right)=x_{e m}^{*}(\bar{K})=x_{i m}^{*}(\bar{K}) \geq x_{i m}^{*}(K)
$$

for all $K \leq \bar{K}$. This gives

$$
V_{i}(x)-C \geq L_{i}(x ; K) \text { for } K \leq \bar{K}
$$

so that

$$
F\left(y^{*}\right)=\int_{\max \left\{K_{L}, x_{e p}^{-1}\left(y^{*}\right)\right\}}^{x_{e m}^{-1}\left(y^{*}\right)}\left\{L_{i}\left(y^{*} ; K\right)-\left[V_{i}\left(y^{*}\right)-C\right]\right\} d \bar{G}(K) \leq 0 .
$$

Since $F(z)$ is a decreasing function and $F\left(z^{*}\right)=0$, so we can deduce that $z^{*} \leq y^{*}$. Recall that $K_{e} \in\left[K_{L}, K_{U}\right]$ and using the assumption $x_{i m}^{*}\left(K_{e}\right)<$ $x_{e m}^{*}\left(K_{e}\right)$ and the above property, we have $\bar{K}<K_{e}<K_{U}$. In summary, we conclude that

$$
z^{*}<y^{*}=x_{i m}^{*}(\bar{K})<x_{i m}^{*}\left(K_{e}\right) .
$$




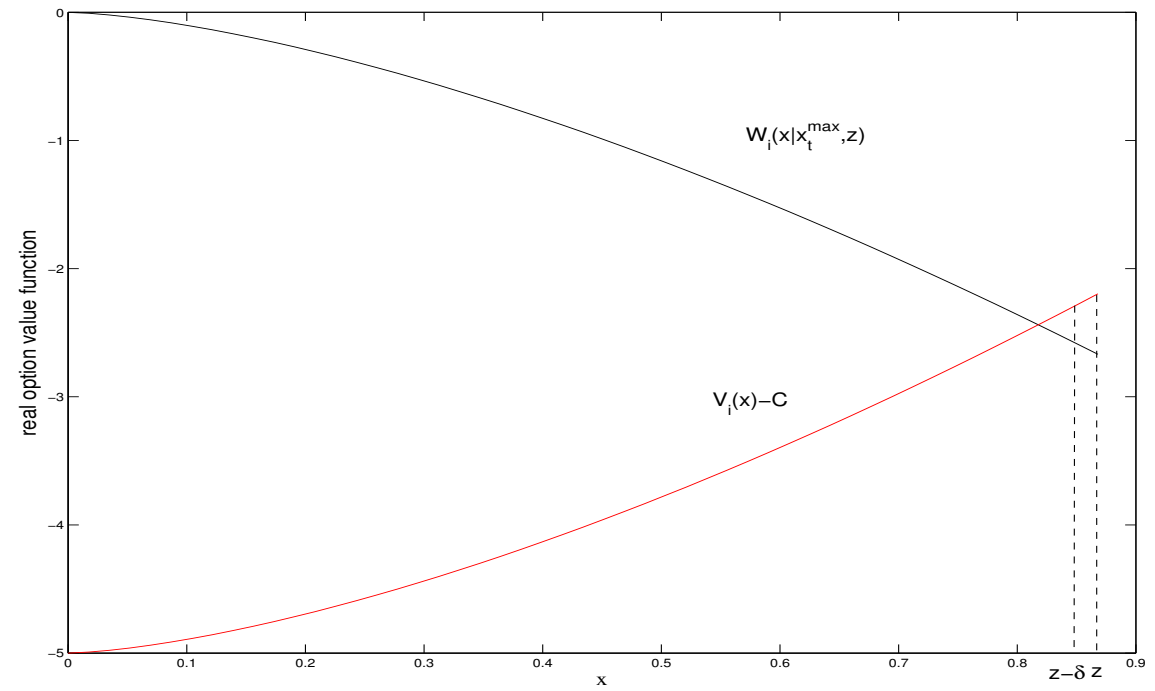

Figure 1a: Plot of the incumbent's real option value of waiting $W_{i}\left(x \mid x_{t}^{\max }, z\right)$ and the real value of holding the patent $V_{i}(x)-C$ with varying values of $x$. When $x$ is sufficiently close to the strategic patent trigger $z$, we observe $W_{i}\left(x \mid x_{t}^{\max }, z\right)<V_{i}(x)-C$. The net difference is smaller in value when $x$ assumes the value of $z-\delta$, where $\delta$ is small and positive, when compared to that when $x$ equals $z^{-}$. Therefore, the incumbent does not benefit from delaying its strategic patent trigger. 


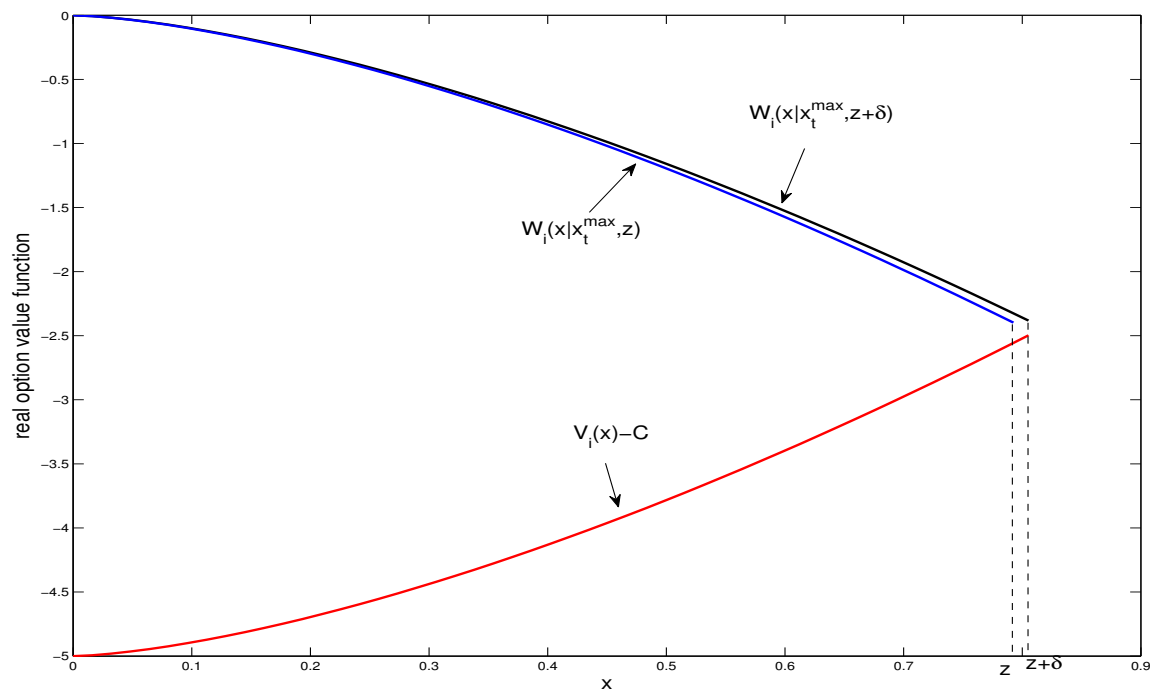

Figure 1b: Plot of the incumbent's real option value of waiting $W_{i}\left(x \mid x_{t}^{\max }, z\right)$ and the real option value of holding the patent $V_{i}(x)-C$ with varying values of $x$. When the chosen value of strategic patent trigger increases from $z$ to $z+\delta$, where $\delta$ is small and positive, the net difference between waiting value and value of holding the patent assumes a higher positive value when $x \rightarrow z^{-}$. Therefore, the incumbent gains more by delaying its strategic patent trigger to a higher threshold. 


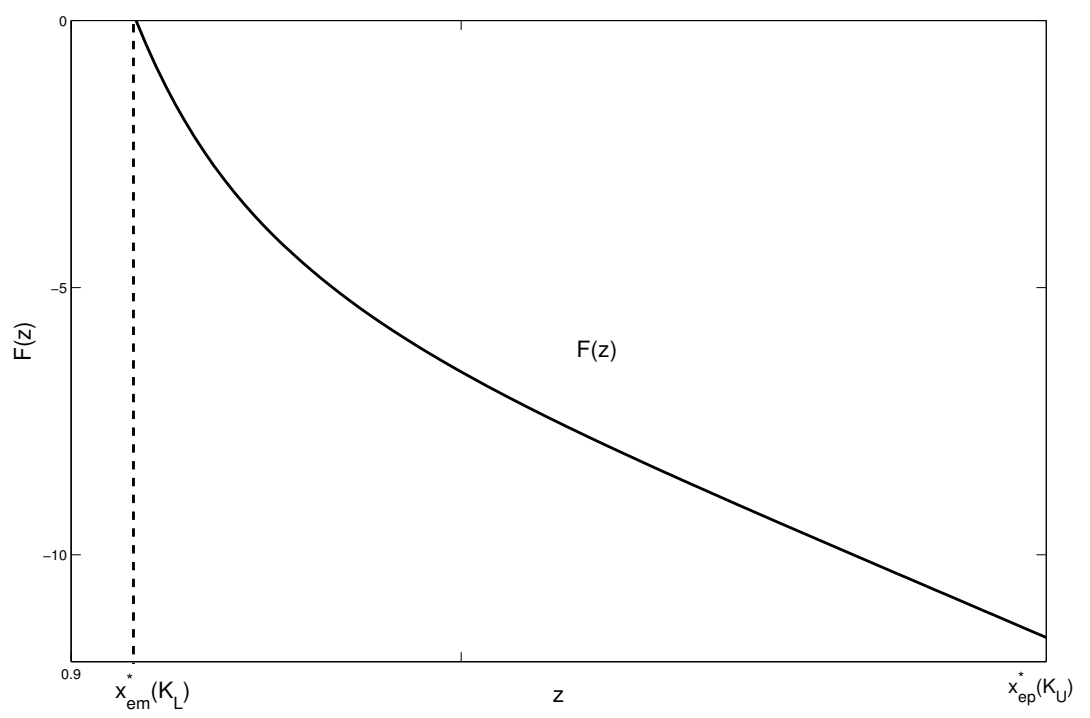

Figure 2a: Plot of $F(z)$ against $z$ for the case where $x_{i m}^{*}\left(K_{L}\right)<x_{e m}^{*}\left(K_{L}\right)$. At $z=x_{e m}^{*}\left(K_{L}\right), F(z)=0$; and for $z>x_{e m}^{*}\left(K_{L}\right), F(z)<0$. 


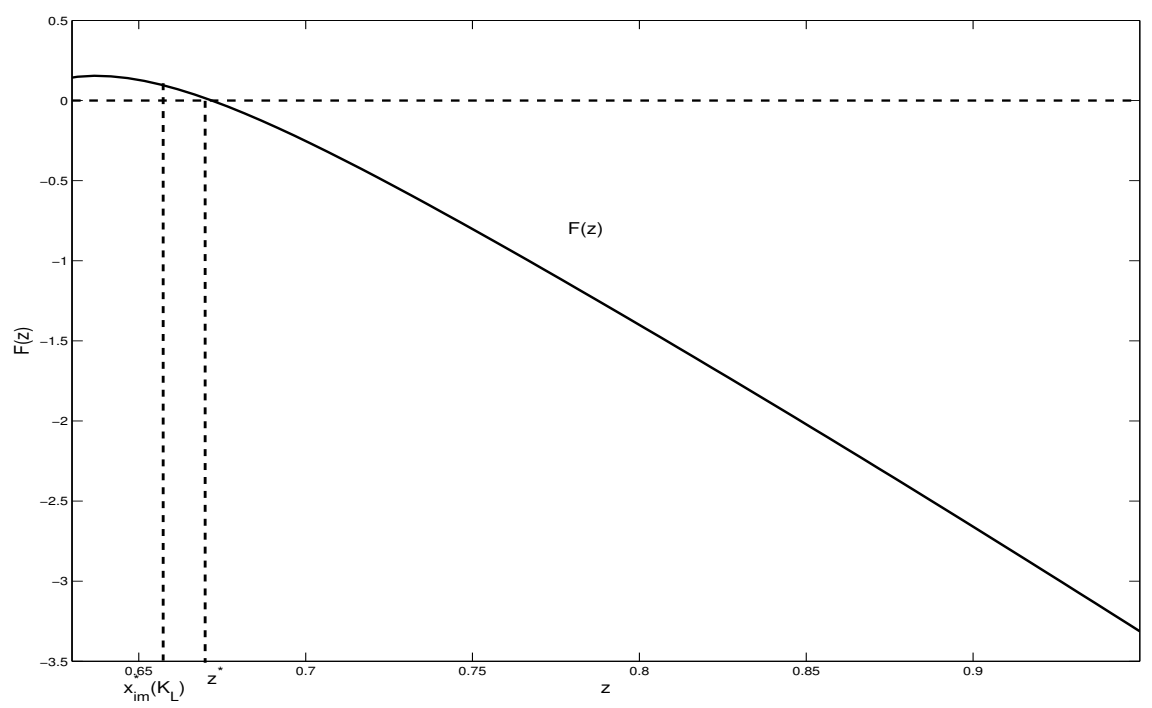

Figure 2b: Plot of $F(z)$ against $z$ for the case where $x_{i m}^{*}\left(K_{L}\right) \geq x_{e m}^{*}\left(K_{L}\right)$. There exists a critical value $z^{*}$ such that $F(z)=0$, where $z^{*}>x_{i m}^{*}\left(K_{L}\right)$. 


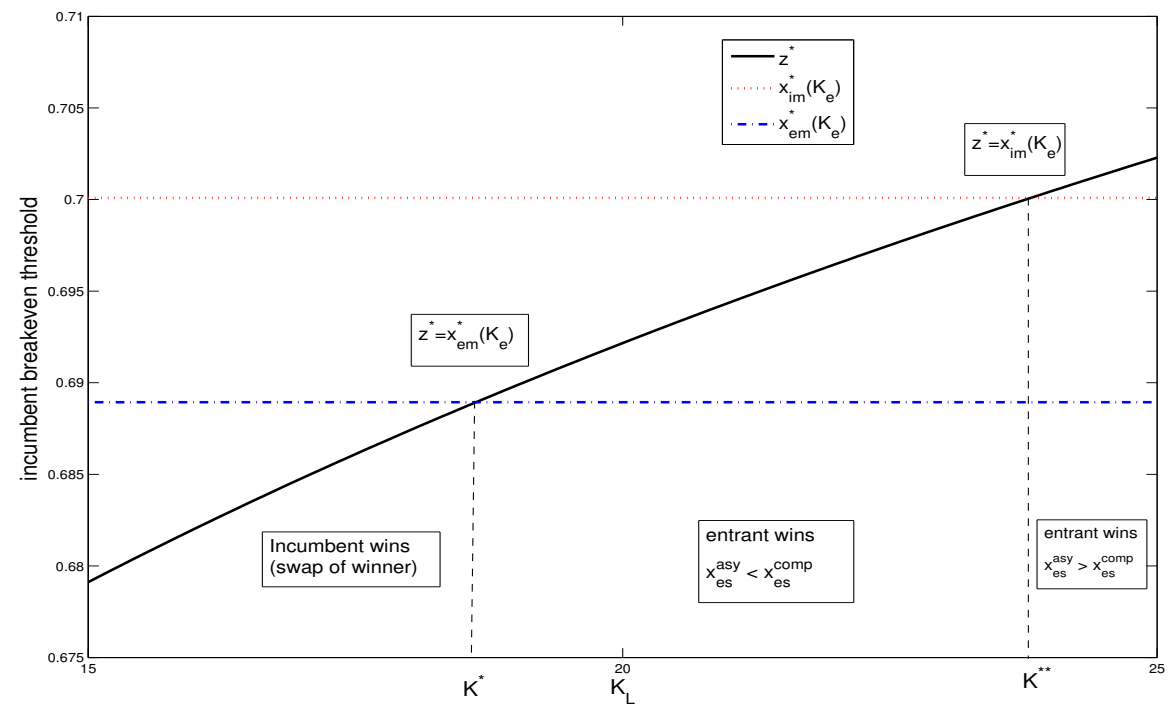

Figure 3: Plot of the incumbent's breakeven threshold $z^{*}$ against $K_{L}$. When $K_{L}<K^{*}$, the incumbent wins under information asymmetry. This represents a swap of winner in the patent race and $x_{i s}^{a s y}=z^{*}$. When $K^{*}<K_{L}<K^{* *}$, the entrant wins and $x_{e s}^{a s y}<x_{e s}^{c o m p}$. When $K_{L}>K^{* *}$, the entrant remains to be the winner and $x_{e s}^{a s y}>x_{e s}^{c o m p}$. This results in some gain in the entrant's real option value due to a higher bias of the distribution of $K_{e}$. 


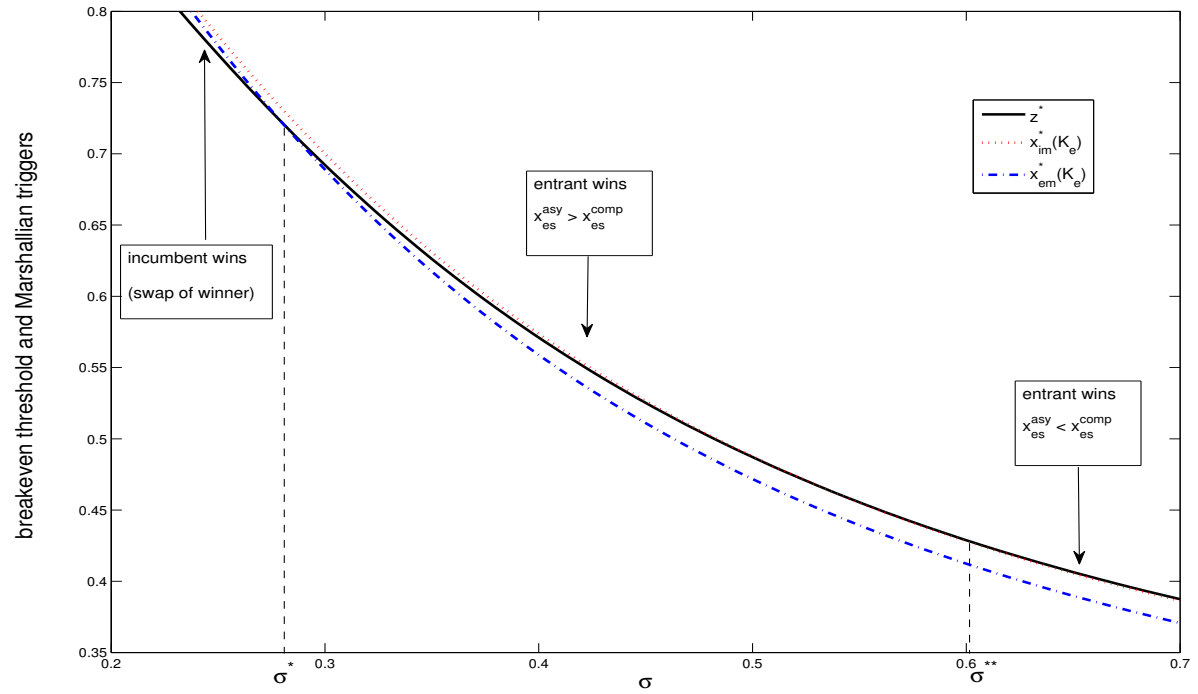

Figure 4: Plot of the incumbent's breakeven threshold $z^{*}$ and the Marshallian triggers of the two firms against the revenue flow volatility $\sigma$. When $\sigma<\sigma^{*}$, the incumbent wins under information asymmetry. This represents a swap of winner in the patent race and $x_{i s}^{a s y}=z^{*}$. When $\sigma^{*}<\sigma<\sigma^{* *}$, the entrant wins and $x_{e s}^{a s y}<x_{e s}^{c o m p}$. When $\sigma>\sigma^{* *}$, the entrant remains to be the winner and $x_{e s}^{a s y}>x_{e s}^{c o m p}$. This results in some gain in the entrant's real option value at a sufficiently high level of volatility $\sigma$. 